\title{
The Incidence of Juvenile Diabetes Mellitus in New Zealand
}

\author{
Jeanette R. Crossley and M. Upsdell \\ Departments of Paediatrics and Community Health, University of Auckland School of Medicine, Auckland, New Zealand
}

Summary. The incidence of juvenile diabetes in New Zealand over a five year period (1968-1972) was determined from hospital admission data stored at the Department of Health, National Statistics Centre. The average annual incidence for persons under 20 years was 10.4 persons $/ 100,000$. There was no sex difference below 16 years, and the increased incidence among females 16-19 years could be attributed to pregnancy. There was a 1.4-fold higher incidence in the South Island than in the North Island. There were no regular seasonal trends. The incidence was constant between 1-9 years increasing to a sustained 2.2-fold higher level from 11 years. The absence of childhood peaks and the sustained higher incidence in adolescence is in contrast to European studies.

Key words: Incidence, seasonal trends, geographical pattern, New Zealand, epidemiology, juvenile onset, diabetes mellitus.

There is considerable interest in possible environmental triggers of juvenile diabetes [1]. Seasonal and age trends which may implicate certain viruses have been reported in some British [1, 2, 3], Swedish [4], Danish [5], French [6], American [7, 8] and Australian [8] populations.

New Zealand is a small country in the Southern hemisphere. The two main islands, North and South (area $1.1 \times 10^{5}$ and $1.5 \times 10^{5} \mathrm{~km}^{2}$ respectively) have a low population $(2,051,363$ and 811,268 respectively in 1971), and low population density, and are separated by a narrow strait; $71 \%$ of the population lives in the North Island. In 1971 there were 434,570 males and 416,981 females aged under 20 years in the North Island, with 163,058 males and 155,804 females under 20 years in the South Island. The present study was undertaken to determine the incidence of juvenile diabetes in New Zealand, and to see whether it varied geographically or with sex, season or age.

\begin{abstract}
Method
The assumption was made that all new cases of diabetes in the age group $0-19$ years would be admitted to a public hospital. For all admissions to New Zealand hospitals a coded diagnosis is stored anonymously at the Department of Health, National Statistics Centre. From these data it was possible to obtain the following information on first hospital admissions for diabetes: hospital of admission, date of admission, sex, age, and sometimes other conditions contributing to the diagnosis.

New Zealand has a predominantly public hospital health care system. Private hospital beds comprise only $20 \%$ of the total, and are mainly in the categories general surgical, maternity and geriatric [9a]. Paediatric cases are admitted to public hospitals; private paediatricians also have access to these beds. It is unusual in New Zealand to commence stabilisation of newly diagnosed diabetes in young persons at home (schemes now operating in the larger centres to introduce insulin therapy to adolescents as out-patients were not instituted in the years under study). We may also have included some persons diagnosed overseas and subsequently admitted to a New Zealand hospital; the error introduced is probably negligible.

The years 1968-1972 were studied, being the latest five for which data were available.
\end{abstract}

\section{Statistical Methods}

\section{Incidences}

The number of cases of diabetes occurring in a year, divided by the number of people in the susceptible population, gives the incidence of diabetes in that year.

Breakdowns of New Zealand's population by age, by island and by sex were obtained from the 1971 Census. The average annual rate of population growth was only $1.4 \%$ for the previous and $1.8 \%$ for the following 5 years, which provides justification for calculating incidences using the 1971 population figures. The effects of age, sex and geographical location (North or South Island) on the observed incidences were studied by standard statistical procedures. 
Choice of Scale: Multiplicative changes in incidences are more meaningful than additive changes. For example, the change in going from an incidence of $1 / 100,000$ to $2 / 100,000$ is comparable in significance to that of going from $10 / 100,000$ to $20 / 100,000$, rather than going from $10 / 100,000$ to $11 / 100,000$. Changing to a $\log$ scale means that multiplicative changes are additive, and thus easier to deal with (10a). The incidences were therefore transformed to a new variable $y=\log (\mathrm{N}+0.5) / \mathrm{p}$ where $\mathrm{N}=$ number of new cases of diabetes over the 5 year period in the respective age, sex, island, group; $\mathrm{p}=$ total population in the respective age, sex, island, group.

Cases were weighted by $\sqrt{\mathrm{N}+1}$ to compensate for differing variances in this scale $(10 \mathrm{~b})$.

Choice of Analysis: A multiple linear regression analysis was performed on the data. This fits a model of the form: $\log$ (incidence) $=\beta_{0}+\beta_{1}$ variable $1+\beta_{2}$ variable $2+\beta_{3}$ variable 3 where variables $1,2,3$, etc. are the variables which enable the closest fit to the data to be made. $\beta_{0}, \beta_{1}, \beta_{2}$, etc. are numbers which give the best prediction. The variables need not be simple contributing factors, e. g. age, but may be functions of the factor, e. g. log (age), polynomials in age, step functions in age.

Thus, the added effects of each variable, over and above the effects of the other factors can be estimated and tested for significant difference from zero.

Variables Initially Tested: The various factors initially tested were geographical location (North or South Island), sex, the interaction island-sex, and age. Several reports in the literature suggest that two peaks in incidence occur, at ages of about 5-7 and 11-13 years $[2,4,5]$. To investigate this possibility polynomials in age up to at least degree 4 would normally be included in the regression analysis. This allows the resulting curve to have two peaks whose heights can be tested for significance. As it is generally advisable to add one or two higher order terms to allow the curve to assume a more complicated shape, terms up to degree 6 were included. The simple polynomials in age - age, age ${ }^{2}, \ldots$ age ${ }^{6}-$ are usually very badly correlated, which makes it difficult to distinguish between the effects of each term. To overcome this problem orthonormal polynomials in age were constructed which are uncorrelated with each other, and each has unit variance, so that the sizes of the coefficients are related to their significance [11].

Variables Subsequently Tested: (a) pregnancy: In the first multiple linear regression run, the incidence of diabetes among females was significantly higher than among males. However, inspection of the data suggested this increase was only in the older age groups. Pregnancy is a predisposing factor to diabetes. However, it was not possible to put in a term to allow for pregnancy since this was not always recorded in the Department of Health records. Of the 111 cases of diabetes in females aged 16 and over, 4 admitted to general hospitals, and 16 admitted to obstetric hospitals, were noted as being pregnant; 9 admitted to obstetric hospitals were not noted as being pregnant. Thus, since at least $25 \%$ of female cases aged 16 and over were pregnant or admitted to an obstetric hospital, a term "possibly pregnant" was introduced which was 1 for women over the age of 16 , and 0 elsewhere. No information is available on the mode of therapy of these pregnant females. As they may not have been truly insulin-requiring it is important to allow for them in the subsequent analysis.

To determine whether the increased incidence for females over 16 years was indeed quite a sudden jump, rather than a gradual increase with age, product terms of each polynomial in age up to the third degree with sex were also added to the regression analysis.

(b) Step function in age instead of polynomials in age: Our data did not show peaks in incidence at any age, but rather a surge to a plateau at 10-11 years. To explore this further we carried out the multiple linear regression analysis again, using step functions instead of polynomials.
The effect of sex at various ages was also explored using step functions.

Seasonal Variation: The possibility of a seasonal variation in incidence was studied by the chi-squared test [12] on the totals for the different months. This analysis concentrates on yearly cycles and detects other cycles poorly. It also ignores the order of the months, and the data is grouped. This is not therefore the most powerful test available.

We also used a more sensitive analysis, the point process spectral analysis [13], which finds the amplitude of the various frequencies of the incidence data, and in particular tests the frequency of the yearly cycle.

\section{Results}

There were 608 new cases of diabetes in the age group 0-20 years for the years 1968-1972, being $119,133,86,109$ and 161 cases per year respectively.

Using the 1971 population census data, the average annual incidence over this period was 10.4 persons per 100,000 under 20 years, the actual incidence being $10.2,11.4,7.3,9.3$, and 13.7 respectively. The incidence trends in various age subgroups, according to sex and geographical location, are summarised in Tables 1 and 2.

The statistical analyses investigated the significance of these observed trends. The results of the multiple linear regression analysis using polynomials in age and step functions are summarised in Tables 3 and 4 respectively. The resulting fit is shown in Figure 1.

Sex: The trends are shown in Figure 1 and Table 3. Whether polynomials or step functions in age were used in the analysis, the incidence of diabetes in

Table 1. Incidence of juvenile diabetes in New Zealand related to age and sex, 1968-1972

\begin{tabular}{|c|c|c|c|}
\hline Age (years) & $0-19$ & $0-15$ & $16-19$ \\
\hline \multicolumn{4}{|l|}{ Males } \\
\hline Total $^{\mathrm{a}}(1971)$ & 597,628 & 492,902 & 104,726 \\
\hline $\begin{array}{l}\text { Newly diagnosed } \\
\text { diabetics }(1968-72)\end{array}$ & 277 & 212 & 65 \\
\hline $\begin{array}{l}\text { Average annual } \\
\text { incidence } / 100,000\end{array}$ & 9.3 & 8.6 & 12.4 \\
\hline \multicolumn{4}{|l|}{ Females } \\
\hline $\begin{array}{l}\text { Total }^{\text {a }} \\
\text { Newly diagnosed diabetics: }\end{array}$ & 572,785 & 472,397 & 100,387 \\
\hline $\begin{array}{l}\text { Not noted as pregnant } \\
\text { pregnant }^{b}\end{array}$ & $\begin{array}{r}301 \\
30\end{array}$ & $\begin{array}{r}216 \\
1\end{array}$ & $\begin{array}{l}85 \\
29\end{array}$ \\
\hline all female diabetics & 331 & 217 & 114 \\
\hline \multicolumn{4}{|l|}{ Average annual incidence: } \\
\hline Not noted as pregnant & 10.5 & 9.1 & 16.9 \\
\hline all female diabetics & 11.5 & 9.2 & 22.7 \\
\hline
\end{tabular}

${ }^{a}$ From 1971 Census figures

${ }^{b}$ Known pregnant, or suspected pregnant because of admission to a women's hospital (Minimum estimate) 
Table 2. Incidence of juvenile diabetes in New Zealand related to age and geographical factors

\begin{tabular}{|c|c|c|c|c|c|c|c|}
\hline & Age & $0-10$ & $11-19$ & $0-19$ & $0-15$ & $16-19$ & $\begin{array}{r}16-19 \\
\text { Males only }\end{array}$ \\
\hline N.I. $^{a}$ & $\begin{array}{l}\text { Diabetics } \\
\text { Total } \\
\text { Incidence }^{b}\end{array}$ & $\begin{array}{r}134 \\
492,903 \\
5.4\end{array}$ & $\begin{array}{r}265 \\
248,638 \\
14.7\end{array}$ & $\begin{array}{r}399 \\
841,441 \\
9.4\end{array}$ & $\begin{array}{r}284 \\
706,421 \\
8.1\end{array}$ & $\begin{array}{r}115 \\
145,130 \\
15.8\end{array}$ & $\begin{array}{r}40 \\
73,743 \\
10.8\end{array}$ \\
\hline S.I. ${ }^{\mathfrak{c}}$ & $\begin{array}{l}\text { Diabetics } \\
\text { Total } \\
\text { Incidence }^{\mathrm{b}}\end{array}$ & $\begin{array}{r}71 \\
178,478 \\
7.9\end{array}$ & $\begin{array}{r}138 \\
140,383 \\
19.8\end{array}$ & $\begin{array}{r}209 \\
318,861 \\
13.1\end{array}$ & $\begin{array}{r}146 \\
258,878 \\
11.2\end{array}$ & $\begin{array}{r}63 \\
59,983 \\
21.0\end{array}$ & $\begin{array}{r}25 \\
30,984 \\
16.1\end{array}$ \\
\hline $\begin{array}{l}\text { S.I. \& } \\
\text { N.I. }\end{array}$ & Incidence $^{b}$ & 6.1 & 16.1 & 10.4 & 8.9 & 17.2 & 12.4 \\
\hline S.I./N.I. & & 1.46 & 1.35 & 1.39 & 1.38 & 1.31 & 1.59 \\
\hline
\end{tabular}

a Average annual incidence per 100,000 persons

b North Island of New Zealand

c South Island of New Zealand

Table 3. Stepwise multiple linear regression analysis of LOG incidence data (0-19 years) against age (using polynomials), geographical location (North or South Island), sex, possible pregnancy, and possible interactions between these

Variables significant at the $5 \%$ level and therefore in the equation

\begin{tabular}{llll}
\hline Variable & $\begin{array}{l}\text { Coefficient to } \\
\text { predict log } \\
\text { (incidence) }\end{array}$ & $\begin{array}{l}\text { Coefficient to } \\
\text { predict } \\
\text { incidence }\end{array}$ & p value \\
\hline Constant & -7.56 & $5.19 \times 10^{-4}$ & $<0.001$ \\
1st degree poly & 8.18 & 3570 & $<0.001$ \\
South Island & 0.367 & 1.44 & $<0.001$ \\
5th degree poly & 4.21 & 67.4 & $<0.001$ \\
Possibly pregnant & 0.551 & 1.73 & $<0.001$ \\
3rd degree poly & -2.10 & 0.122 & $<0.03$ \\
2nd degree poly & -3.13 & 0.0437 & $<0.04$ \\
\hline
\end{tabular}

All other variables had $\mathrm{p}$ values $>0.1$

Multiple correlation coefficient $\left(R^{2}\right)=0.727$

Equation to predict annual incidences: Incidence $=2.93 \times 10^{-5}$ $\exp \left(4.84 \times 10^{-5} \mathrm{age}^{5}-2.39 \times 10^{-3} \mathrm{age}^{4}+0.0416 \mathrm{age}^{3}-\right.$ 0.300 age $^{2}+0.872$ age). Multiply by 1.44 if in the South Island. Multiply by 1.73 if female and over 16 years old

females aged 16 years and over increased suddenly and significantly ( 1.5 fold, $95 \%$ confidence interval 1.24-1.83), compared with that of males in the same age range. Pregnancy was a major reason for this difference. There was no significant difference in the incidences between the sexes below the age of 16 .

Pregnancy: Our data confirm that pregnancy is a significant risk for diabetes. $6.8 \%$ of females aged 15-19 years were pregnant each year during the interval being studied ( $9 \mathrm{~b})$. Thus the incidence of diabetes among pregnant women aged 15-19 years was at least $67 / 100,000$, more than 5 times the incidence for males aged 16-19 years.

Age: The age-related incidences are shown in Figure 1. In the regression analysis with polynomials in age,
Table 4. Stepwise multiple linear regression analysis of log incidence data (0-19 years) against age (using step functions), geographical location (North or South Island), sex, and the interaction between age and sex (using step functions)

Variables significant at the $5 \%$ level and therefore in the equation

\begin{tabular}{llll}
\hline Variable & $\begin{array}{l}\text { Coefficient to } \\
\text { predict log } \\
\text { (incidence) }\end{array}$ & $\begin{array}{l}\text { Coefficient to } \\
\text { predict } \\
\text { incidence }\end{array}$ & p value \\
\hline Constant & -10.48 & $1.4 \times 10^{-4}$ & $<0.001$ \\
South Island & 0.363 & 1.44 & $<0.001$ \\
Female 16 \& over & 0.409 & 1.51 & $<0.001$ \\
Age 1 \& over & 0.837 & 2.30 & $<0.01$ \\
Age 11 \& over & 0.447 & 1.56 & $<0.01$ \\
Age 10 \& over & 0.341 & 1.41 & $<0.01$ \\
\hline
\end{tabular}

All other step functions had $p$ values $>0.07$

Multiple correlation coefficient $\left(\mathbf{R}^{2}\right)=0.733$

Predicted annual incidences

\begin{tabular}{lcccc}
\hline Age & Male & \multicolumn{3}{c}{ Female } \\
\hline & North & South & North & South \\
& Island & Island & Island & Island \\
0 & 2.8 & 4.0 & 2.8 & 4.0 \\
$1-9$ & 6.4 & 9.2 & 6.4 & 9.2 \\
10 & 9.0 & 13.0 & 9.0 & 13.0 \\
$11-15$ & 13.6 & 19.6 & 13.6 & 19.6 \\
$16-19$ & 13.6 & 19.6 & 20.5 & 29.5 \\
\hline
\end{tabular}

the first and fifth order terms in age were highly significant, indicating a change in incidence with age. However, analysis of the best fit polynomials showed that there were no significant differences between the individual fluctuations. Thus, our data did not show the two peaks in incidence previously reported $[2,4$, 5], but rather a marked step at about 11 years: the average incidence increased 2.2 fold. Indeed, by fitting step functions instead of polynomials the number of age parameters needed was reduced from 4 to 3 , 

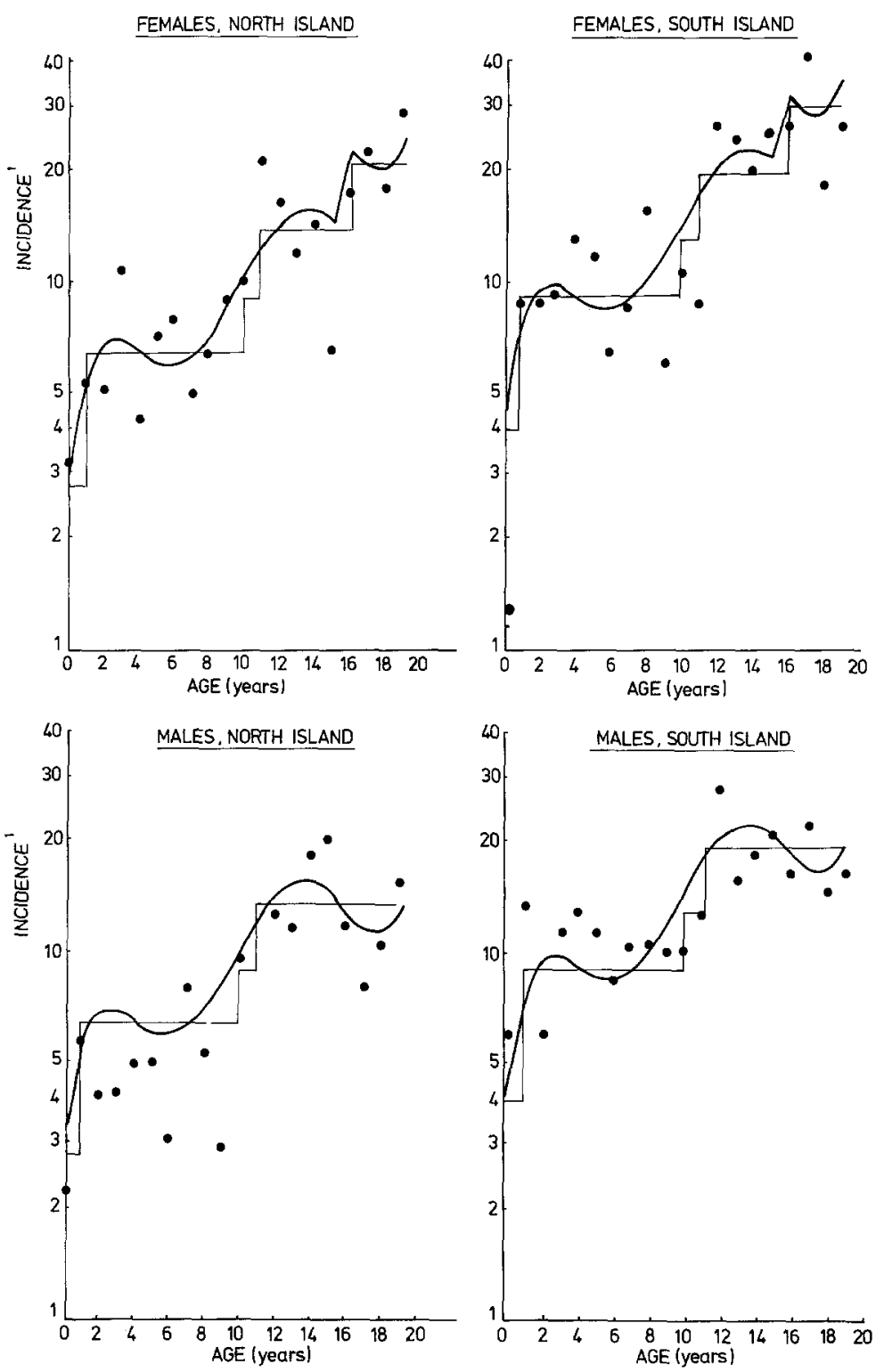

Fig. 1. Incidence of juvenile diabetes in New Zealand, related to age of onset: actual incidences. Step functions and polynomials have been fitted. ${ }^{1}$ Average annual number of new cases per 100,000 for the period $1968-1972$

and the percentage of the variance explained increased from $72.7 \%$ to $73.3 \%$. Analysis carried out using males only 0-19 years and females under 16 years gave similar conclusions. The reason babies less than 1 year old have an abnormally low incidence is not clear, but may be related to the relative immaturity of their immune system.

Geographical: The regression analyses showed that being in the South Island multiplied the risk of diabetes by 1.44 (95\% confidence interval 1.24-1.66), regardless of age.

Seasonal: Our study did not show a seasonal variation in incidence. The chi-squared value was $12.0, \mathrm{p}$ $=0.6,11$ degrees of freedom. Moreover the point process spectral analysis showed that the frequency corresponding to a yearly cycle of incidence was negligible.
The latter analysis did, however, find that the 3.3 yearly cycle was significant at the $5 \%$ level. Since the time span of the data collection was only 5 years, this cycle is due to only 2 periods of increased incidence, one at the beginning of 1969 , and the other in the middle of 1972 (Fig. 2). Thus the incidence of diabetes was not uniform over the period, but no regular pattern could be discerned.

\section{Discussion}

The average annual incidence of juvenile diabetes in the present study $(10.4 / 100,000$, range $7.3-13.7)$ is similar to that previously reported: in the U. K. [3], ages 0-15, 7.7; in Denmark [5], ages 0-29, 13.2; in France [7] ages 0-14, 3.7; in Norway [14], ages $<10$ and $10-19,7$ and 13 respectively; in Rochester, 


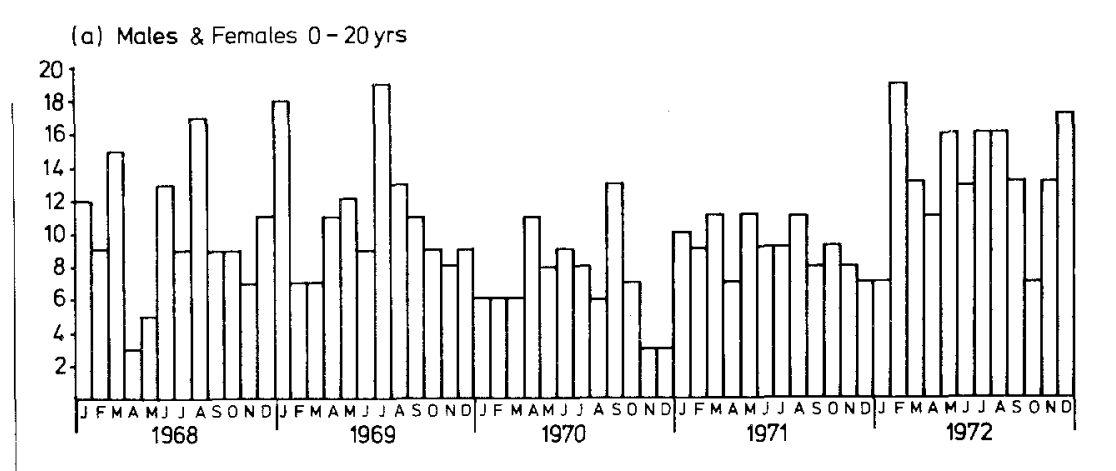

(b) Males 0 -20yrs

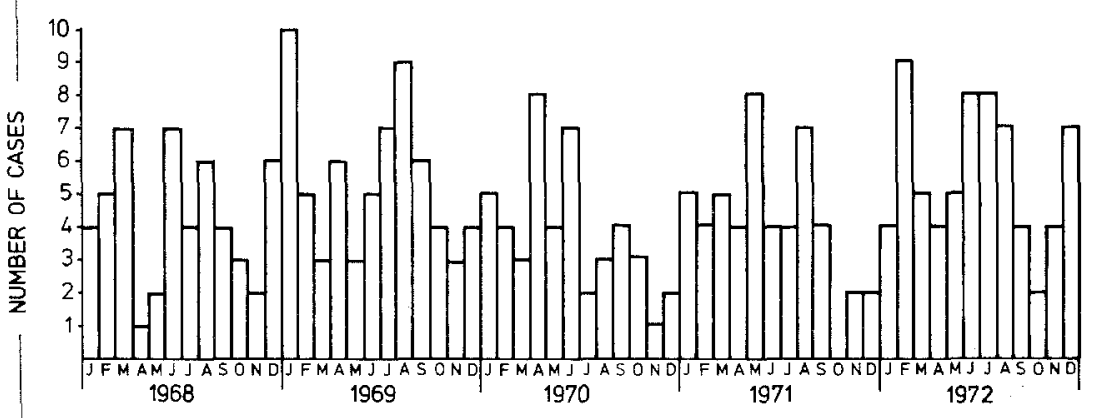

(c) Males \& Females $0-15 y r s$

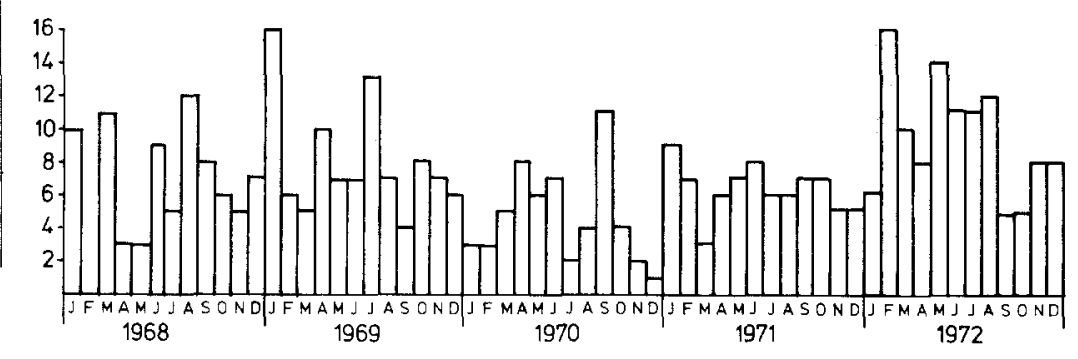

Fig. 2. Number of cases of juvenile diabetes per month in New Zealand, during the interval January 1968-December 1972
U.S.A. [15], ages $0-14,19.6$. Because of the small numbers of subjects in some of these studies, it is difficult to know whether any of the differences in incidences are significant.

Several factors may contribute to the higher incidence of diabetes found in the South Island in our study. First, the Census figures for 1971 indicate differences in the ethnic distribution of the population. In the South Island, 97\% were European, 1.7\% Maori, $0.4 \%$ other Polynesian, $0.9 \%$ other. In the North Island, 86\% were European, 10\% Maori, 2\% other Polynesian, and $2 \%$ other. These figures had changed little from those in the 1966 Census, when Europeans comprised $98 \%$ of the South Island, and $88 \%$ of the North Island population. However, even if the minor ethnic groups never succumb to juvenile diabetes, the incidence in the South Island would be increased only 1.1 fold.

A second factor is the more severe climate experienced in the South Island, which may affect the body's reaction to viral infections. A third factor may be population density, which affects the spread of viral infections. In the lower-populated South Island, the actual population density in the cities (960 persons $/ \mathrm{km}^{2}$ ) was nearly double that of North Island cities $\left(510\right.$ persons $\left./ \mathrm{km}^{2}\right)$. We have not been able to relate the increased incidence to socio-economic differences.

In contrast to our experience in New Zealand, some studies have reported significant seasonal trends in incidence: a lower incidence in May and June in Europe (studies collated by Gamble [2]) and a lower incidence in some cities in the U.S.A. [8] in June, July, August and September than in the other months. Similar trends have been suggested for Sweden [4] and Denmark [5], but do not reach significance.

Our failure to demonstrate regular seasonal fluctuations in diabetes diagnosis in New Zealand may be related in part to the occurrence in our summer of the Christmas season, with its accompanying mobility of populations, parties, and tendency to excessive caloric intake. In autumn and winter the greater number of viral infections may increase the incidence of diabetes. In the Northern Hemisphere the occurrence together of at least these two precipitating fac- 
tors may accentuate a peak incidence at this time; in New Zealand the two effects are offset by 6 months. Moreover, much of New Zealand enjoys a milder climate than England and Scandinavia.

The average incidence of diabetes was 2.2 fold higher in the age range 11-19 years than in the range 1-9 years. This suggests that physiological changes around puberty may increase the propensity to diabetes. It is interesting that the increased propensity remained at least until 19 years. This trend differs from that of Gamble [2] and Bloom et al. [3], where after a "pubertal" peak, the number of cases declined dramatically in the teenage years. Since absolute numbers of cases, rather than true incidences, were used, some of this effect may have been due to the age structure of their general population. Christau et al. [5], however, using true incidences, reported a similar trend. Although the age range of their subjects is only $0-15$ years, Fleegler et al. [8] also report an abrupt decline in incidence after age 13. They suggest, however, that it may in part be artifactual since their data were collected from paediatric sources.

All methods of data collection that have been used for studying the incidence of diabetes, are subject to some criticism. For those studies which rely on individual doctors sending a report to a central bank, inadequate notification of cases in late adolescence may contribute to the apparently lower incidence at those ages. When hospital records are used, each admission has been automatically coded, and, in New. Zealand, housed in a central computer. Because of the nature of the Health Care System in New Zealand, omissions due to home stabilisation of new cases would have been negligible.

The altered distribution of age-related incidence compared with that of European studies [2, 4, 5], namely the absence of childhood peaks and the sustained relatively higher incidence in adolescence, may be due in part to the fact that New Zealand's population density both as a nation and within major cities is $10-20 \%$ that of Europe. It has been suggested by Gamble [2] that in those who are generally susceptible, pancreatic damage which finally results in diabetes may be cumulative. That our average annual incidence is similar to that reported in European and American studies seems to indicate, however, that any long-term protective effect of our low population density is relatively minor.

Acknowledgements. We gratefully acknowledge the assistance of the Staff of the National Health Statistics Centre, Department of Health, without whose willingness to hand-sort data, this study could not have been undertaken; the Medical Research Council of New Zealand for funds (M.P.U.); and Professor R. B. Elliott for useful suggestions.

\section{References}

1. Cudworth, A. G., Gamble, D. R., White, G. B. B., Lendrum, R., Woodrow, J. C., Bloom, A.: Aetiology of juvenile-onset diabetes. Lancet 1977 I, 385-388

2. Gamble, D. R.: Epidemiological and virological observations on juvenile diabetes. Postgrad. Med. J. 50 (Suppl. 3), 538-543 (1974)

3. Bloom, A., Hayes, T. M., Gamble, D. R.: Register of newly diagnosed diabetic children. Br. Med. J. 1975 III, 580-583

4. Sterky, G., Holmgren, G., Gustavson, K. H., Larsson, Y., Lundmark, K. M., Nilsson, K. O., Samuelson, G., Thalme, B., Wall, S.: The incidence of diabetes mellitus in Swedish children 1970-1975. Acta Paediatr. Scand. 67, 139-143 (1978)

5. Christau, B., Kromann, H., Ortved Andersen, O., Christy, M., Buschard, K., Arnung, K., Hojland Kristensen, I., Pietersen, B., Steinrud, J., Nerup, J.: Incidence, seasonal and geographical patterns of juvenile-onset insulin dependent diabetes mellitus in Denmark. Diabetologia 13, 281-284 (1977)

6. MacMillan, D. R., Kotoyan, M., Zeidner, D., Hafezi, B.: Seasonal variation in the onset of diabetes in children. Pediatrics 59, 113-115 (1977)

7. Lestradet, H., Besse, J.: Prévalence et incidence du diabète juvénile insulino-dépendant en France. Diabete Metab. 3, 229-234 (1977)

8. Fleegler, F. M., Rogers, K. D., Drash, A., Rosenbloom, A. L., Travis, L. B., Court, J. M.: Age, sex, and season of onset of juvenile diabetes in different geographic areas. Pediatrics 63, 374-379 (1979)

9. New Zealand Department of Health Publication: Trends, health and health services. (a) 170; (b) 51 (1965)

10. Cox, D. R.: (a) Linear logistic model; (b) Empirical logistic transform. In: Analysis of binary data, (a) pp. 14-29; (b) pp. 30-42. London: Chapman and Hall 1970

11. Seber, G.A.F.: In: Linear regression analysis, chapter 8, pp. 214-238. New York: Wiley and Sons 1977

12. Draper, N., Smith, H.: Applied regression analysis. New York: Wiley and Sons 1966

13. Billinger, D.: Time series analysis, data analysis and theory. New York: Holt, Rhinhart and Winston 1975

14. Ustvedt, H. J., Olsen, E.: Incidence of diabetes mellitus in Oslo, Norway 1956-65. Br. J. Prev. Soc. Med. 31, 251-257 (1977)

15. Palumbo, P. J., Labarthe, D. R.: The incidence of diabetes mellitus in Rochester, Minnesota, 1945-1969. Adv. Metab. Disord. 9, 13-28 (1978)

Received: July 10, 1978, and in revised form: July 23, 1979

J. R. Crossley, Ph. D.

Department of Paediatrics

School of Medicine

University of Auckland

Private Bag

Auckland, New Zealand 